\title{
Programas intergeracionais: quão relevantes eles podem ser para a sociedade brasileira?
}

\author{
Intergenerational programs: how important are they to brazilian society?
}

Lucia Helena de Freitas Pinho França' Alcina Maria Testa Braz da Silva ${ }^{1}$ Márcia Simão Linhares Barreto'

\section{Resumo}

Em 2020, a expectativa de vida no Brasil ultrapassará os 75 anos, representando 34 milhões de idosos, ou seja, $15 \%$ da população. Apesar de o envelhecimento ser um fenômeno ainda recente, a população dos idosos brasileiros é uma das maiores do mundo. O país precisa adotar medidas principalmente na área econômica, na educação, saúde e de serviços sociais, para que o envelhecimento se torne um ganho real. Algumas dessas medidas devem incluir as crianças e os jovens, de forma a prevenir os preconceitos quanto ao envelhecimento e possíveis conflitos intergeracionais que a sociedade poderá enfrentar diante das necessidades e dos recursos disponíveis. O objetivo deste artigo é ressaltar a importância dos programas intergeracionais para a quebra de preconceitos frente ao envelhecimento (ageismo), desenvolvendo atitudes que possam estimular a solidariedade e cidadania na sociedade contemporânea.

\section{Abstract}

In 2020, Brazilian life expectancy will be over 75 years old, representing 34 million citizens or 15 percent of population. Although ageing is a recent phenomenon, Brazilian elderly population is one of the largest in the world. The country needs to address policies especially economic ones, education, health and social services so that ageing represents a real gain. Some of these measures should include children and teenagers, in order to prevent prejudice against the elderly and ease possible intergenerational conflicts, which society may face due to its needs and available resources. The purpose of this paper is to emphasize the importance of breaking down the prejudice against elderly (ageism) developing attitudes that can improve movements toward solidarity and citizenship in contemporary society.
Palavras-chave: Programas Intergeracionais. Velhice. Conflito de Gerações. Preconceito. Educação Não-formal. Cidadania e Solidariedade.

\author{
Key words: \\ Intergenerational \\ Programs. Ageing. \\ Intergenerational Conflict. \\ Prejudice. Non-formal \\ Education. Citizenship \\ and Solidarity.
}

\footnotetext{
Universidade Salgado de Oliveira, Conselho de Ensino, Pesquisa e Extensão, Programa de Pósgraduação em Psicologia. Niterói, RJ, Brasil 


\section{INTRODUÇÃO}

O envelhecimento populacional é um dos maiores desafios da atualidade, mas nem todos os países estão preparados para lidar com esta realidade. No Brasil, a expectativa de vida em 1940 era de 41,5 anos. Setenta anos depois, esta expectativa saltou para 73 anos, e as projeções do IBGE $^{1}$ apontam que, em 2020, a expectativa de vida ultrapassará os 75 anos. Nesta época, o país terá um contingente de 34 milhões de idosos, representando $15 \%$ da população. $O$ aumento populacional de pessoas idosas ainda é um fenômeno recente dentro da realidade brasileira, e muitas ações, principalmente na área econômica, de educação, saúde e de serviços sociais, precisam ser tomadas para evitar que o envelhecimento, que é um ganho, seja reduzido a um problema.

$\mathrm{Na}$ outra ponta geracional estão as crianças entre 0-14 anos. Esta clientela é prioritária em atendimento governamental, apesar de a evidente queda da fecundidade e natalidade ter provocado, em apenas dez anos, uma drástica redução neste contingente, que, em 1995 representava um terço da população (32,5\%) e em 2005 , um quarto dos habitantes $(26,5 \%)^{1}$. Muitas medidas precisam ainda ser tomadas para melhorar o nível de desenvolvimento deste segmento.

Apesar dos esforços e medidas governamentais como o Bolsa-Família* e o Programa de Aceleração do Crescimento-PAC ${ }^{* *}$, grande parte dos estudantes da rede pública recebe educação deficitária. Por sua vez, seus professores possuem formação inadequada e recebem salários aquém das suas necessidades. Esta cadeia de causa e consequência acaba por refletir no fracasso e evasão escolar e na dificuldade de futura empregabilidade desses jovens. A sociedade vê emergir a falência nos valores éticos e morais, estimulada pela corrupção, impunidade e pelo aumento da criminalidade, num círculo que precisa ser quebrado. Pesquisa recente realizada pelo IBOPE, em parceria com o movimento Todos pela Educação, revelou que um dos maiores problemas na educação pública é a violência nas escolas, provocada pela falta de segurança e das drogas ${ }^{2}$.

Associada a essa insegurança nas escolas, há uma quase que ausência de exemplos a serem seguidos pelos jovens. A perda de valores éticos e morais é reforçada pela impunidade e a criminalidade, que aumentam dia a dia e desencadeiam um quadro de instabilidade e de desesperança. A família vai mal, e com ela os relacionamentos, o diálogo e o repasse de valores. Esta modificação na estrutura da rede familiar, em parte provocada pelo processo urbano e migratório, empurrou muitas famílias a residirem próximas ao local de trabalho e distante dos familiares de outras gerações. Consequentemente, a falta de oportunidades de convívio com os avós (avôs) provocou o afastamento afetivo e um sentimento de estranheza e de desconhecimento frente ao envelhecimento e aos idosos, que podem levar à formação de estereótipos e preconceitos.

Não apenas o afastamento afetivo, mas um eminente conflito intergeracional deve ser levado em consideração ao serem propostos programas que atendam duas ou mais gerações. Goldani ${ }^{3}$ aponta que os filhos podem ser muitas vezes o suporte econômico para os idosos, seja pela corresidência, seja pela transferência de recursos, embora estas transferências possam vir também dos próprios idosos, que são chefes de famílias extensas. O aumento considerável da população idosa e os inúmeros programas sociais voltados para eles poderão favorecer a percepção do conflito intergeracional, embora grande parte dos programas sociais existentes no Brasil tenha beneficiado toda a família.

Como lembrado por Goldani ${ }^{3}$, o plano da Assembleia de Envelhecimento Mundial em Madri ${ }^{4}$ incentiva a solidariedade intergeracional

Programa Bolsa Família. Criado pela Lei 10.836, de 9 de janeiro de 2004. Disponível em URL: http://bolsafamilia.datasus.gov.br/ w3c/bfa.asp

** Programa de Aceleração do Crescimento-PAC. Brasília, DF, 2007. Disponível em URL: http://www.brasil.gov.br/pac 
tanto na família, comunidade e Estado, em função de uma sociedade melhor para todas as idades. Merz, Schuengel e Schulze ${ }^{5}$ caracterizam a solidariedade como um conjunto de interesses, propósitos e simpatias entre os membros de um grupo que pode ser uma família. A solidariedade estaria relacionada a um contexto social, através de um componente moral, uma organização social e uma interação.

A solidariedade intergeracional pode reverter não só na quebra de preconceitos sociais frente ao envelhecimento, como na melhoria da qualidade de vida de jovens e idosos. Antonucci ${ }^{6}$ ressalta que a maneira como o indivíduo constrói e interpreta as situações nas relações sociais produzem um efeito na sua saúde e bem-estar. As pessoas que vivenciam aspectos positivos nas relações de apoio intergeracional sentem-se mais positivas em relação a si próprias e ao seu mundo, suportando melhor a doença, o stress e outras dificuldades.

O convívio dos idosos com os seus filhos e netos pode beneficiar mutuamente as gerações, no sentido do aprimoramento dos conhecimentos em relação a história familiar, a cidade onde residem, ao mundo, e fora do contexto familiar, pode facilitar o estabelecimento de uma nova amizade/afetividade que desencadeie a solidariedade, e o desenvolvimento cognitivo social. Como apontado por França \& Soares ${ }^{7}$, a afetividade assim como a sociabilidade e a comunicação podem ser desenvolvidas a vida inteira. Sob o ponto de vista pragmático, o estímulo à solidariedade, por meio da quebra de preconceitos, poderá ser obtido quando houver um ambiente propício para o conhecimento recíproco entre as gerações.

Programas intergeracionais nas comunidades, escolas e organizações podem beneficiar mutuamente os jovens e os idosos, independentemente dos laços familiares. Representam uma oportunidade para discutir os preconceitos existentes entre as faixas etárias, bem como os problemas nacionais e locais nas escolas e nos centros comunitários, de forma que as pessoas possam vislumbrar alternativas para o bem-estar coletivo. Como Seminério ${ }^{8}$ enfatizou, deve existir um canal aberto para que as trocas interpessoais contribuam para a adaptação aos ciclos de vida.

O valor do contato das crianças com os idosos é irrefutável para o resgate de valores, para a noção de tempo, a transformação ao longo dos anos e $\mathrm{da}$ identidade parental ${ }^{7}$. As atividades desenvolvidas entre gerações, por exemplo, entre os idosos e as crianças, devem ser permeadas pelo processo dialético, onde precisam estar presentes as situações concretas da comunidade, o processo de envelhecimento e as medidas a serem tomadas pela sociedade para garantir a mobilidade, a participação social e a independência daquele que envelhece - recomendações da Organização Mundial de Saúde em sua Política do Envelhecimento Ativo?

\section{O CONCEITO DE GENERATIVIDADE E 0 LEGADO PARA 0 FUTURO}

Erikson ${ }^{10}$, no seu modelo de desenvolvimento psicossocial ao longo da vida, foi o primeiro autor a introduzir o termo "generatividade", no sétimo estágio de vida, como o contraponto à estagnação na meia idade. Em seu modelo, o autor assinalou a importância do relacionamento intergeracional harmonioso ao longo da vida. A generatividade é definida por ele como uma tarefa social importante para a vida adulta, necessária para a transição bem-sucedida à fase final de integridade.

McAdams \& de St Aubin ${ }^{11}$ definiram a generatividade como uma preocupação e comprometimento do adulto para com as gerações futuras. Este comprometimento envolveria o ensinamento dos pais, dos professores ou tutores, para que possam deixar um legado positivo de si próprio para o futuro. McAdams $\&$ de St Aubin ${ }^{12}$ destacam sete aspectos no seu modelo de generatividade: i) demandas culturais; ii) desejo íntimo; iii) preocupação com a geração futura; iv) crença nas espécies; v) comprometimento com os objetivos; vi) criatividade e manutenção da ação; e vii) expressão narrativa em contar a estória de vida de alguém. 
De acordo com McAdams \& de St Aubin ${ }^{11}$, a generatividade pode ser manifesta pelo modo pelo qual um adulto descreve o sentido de sua vida, ou descrita como a criação de uma pessoa de meiaidade em função de um futuro imaginário, em que crenças e valores estão relacionados aos eventos-chave na vida. Se por alguma razão, as pessoas perdem a credibilidade nesse futuro imaginado, a identidade é então ameaçada. Neste sentido, os indivíduos precisam encontrar meios de como relacionar coerentemente este futuro diferente com o passado e o presente.

Magalhães \& Gomes ${ }^{13}$ apontam que o sentimento de generatividade estimularia o cuidado, o ensinamento, a liderança e a promoção do bem-estar da próxima geração pelos mais velhos. Segundo eles, há uma relação positiva entre generatividade e o comprometimento de carreira, e ressaltam e importância das atividades generativas situadas no contexto da vida profissional e as demais atividades significativas do indivíduo na comunidade, tais como a participação em movimentos sociais, trabalho voluntário, associações civis, clubes, etc.

Ainda de acordo com Magalhães \& Gomes ${ }^{13}$, a importância do trabalho para os indivíduos tende a fortalecer a relação de generatividade e carreira. Por outro lado, pessoas que tenham características empreendedoras podem perceber sua identidade mais conectada com a capacidade de iniciar e programar empreendimentos que abandonarão num curto ou médio prazo, a fim de se dedicar a outro desafio. Talvez estas pessoas pudessem participar de projetos variados intergeracionais na comunidade com prazo determinado. Isto poderia trazer a elas um sentimento de realização complementar à carreira.

Guttman (1987, citado por Coleman \& Podolskij, 2007) ${ }^{14}$ apontou as vantagens de uma cultura coerente e estável, na qual grupos etários sucessivos se reconhecem de acordo com as fases que as pessoas estejam vivenciando. Este reconhecimento traria o senso de generatividade. Guttman afirmou ainda que quando as práticas e normas sociais de uma sociedade mudam vertiginosamente, a habilidade dos mais velhos passam seus conhecimentos para os mais jovens, torna-se limitada, e esta limitação acaba por afetar o senso de generatividade.

Coleman \& Podolskij ${ }^{14}$ examinaram como o senso de continuidade de identidade dos veteranos de guerra soviéticos teria sido afetado pelas recentes mudanças na sociedade na Rússia e na Ucrânia. Eles buscaram evidências nos processos pelos quais a identidade, e em particular, o senso de generatividade, foi mantido ou perdido e recuperado. Esses pesquisadores entrevistaram 50 veteranos de guerra acerca da satisfação com a vida, da autoestima e da generatividade. A grande maioria dos pesquisados assinalou que as mudanças na Rússia e na Ucrânia resultaram em uma consequência desastrosa desde a ruptura da União Soviética, e muitos ainda preferiam o regime soviético de outrora, reclamando da falta de coesão social e de solidariedade com o novo regime. Apesar disto, a maior parte dos participantes demonstrou um alto senso de generatividade, bem-estar e um forte sentimento de esperança no futuro das suas famílias, demonstrando resiliência e uma resistência dos laços familiares com a antiga nação soviética.

Este e outros estudos podem ser replicados em comunidades cariocas que já foram mais violentas e que, se pacificadas, poderiam abrigar programas comunitários intergeracionais. Talvez o primeiro resultado fosse o reforço da sensação de segurança e de bem-estar entre os participantes, de viver sem a violência brutal com a qual conviviam anteriormente. Outros resultados esperados são o resgate de valores, da cidadania e da esperança, por meio de atividades sistemáticas idosos-crianças, priorizando a discussão das necessidades das comunidades.

Analisar a situação de risco a qual a comunidade está envolvida não deve ser necessariamente o objetivo de uma proposta intergeracional, mas a violência urbana poderá emergir nas discussões sobre solidariedade e cidadania. Estas discussões poderão trazer à tona as alternativas para a preservação da vida, da identidade e das funções individuais dentro do coletivo e do bem comum. 
ATIVIDADES INTERGERACIONAIS COMO COADJUVANTES NA FORMAÇÃO DE ATITUDES SOLIDÁRIAS E CIDADÃS

Um dos mais importantes requisitos para o desenvolvimento individual humano é o relacionamento entre pais e filhos, que traz consequências por toda a vida. A qualidade deste relacionamento pode ser medida por três indicadores: intimidade, admiração e proximidade emocional entre pais e filhos, como apontaram Schwarz et al. ${ }^{15}$. Estes pesquisadores indicaram ainda que quanto maior a intimidade e proximidade emocional da filha em relação à mãe, maior seria o apoio emocional fornecido por ela aos pais. E, quanto maior a admiração, interdependência e expectativas de dotes familiares pela filha, maior também o apoio instrumental fornecido por ela a seus pais.

Em muitos casos, as avós exercem papéis muito importantes no complemento deste desenvolvimento dos mais jovens. Pais, filhos e avós são influenciados por aspectos sócio-culturais, e responsáveis pela transmissão de valores na família e na comunidade. O relacionamento familiar é, assim, primordial para a preservação dos padrões de comportamento na sociedade.

Entretanto, este relacionamento familiar nem sempre ocorre nos moldes do ideal, principalmente porque na atualidade cada vez é mais intensa a participação das mães e pais no mercado de trabalho. Por outro lado, com o aumento do número absoluto de idosos e da postergação da idade da aposentadoria, diversos trabalhadores mais velhos precisam continuar ativos. Esta participação intensa de toda a família no mercado de trabalho, apesar de ser importante para a economia do país, força a escola a assumir uma responsabilidade quase que integral $\mathrm{da}$ educação das crianças, e que de fato não tem sido cumprida.

Há, sem dúvida, uma lacuna na educação dos filhos por parte dos pais e avôs. Neste sentido, são reduzidas as trocas afetivas, a transmissão dos valores morais e éticos, e mesmo a passagem de cultura e do patrimônio, tão importantes para a formação de valores e das atitudes de um adulto. Reitzes \& Mutran ${ }^{16}$ indicaram que o papel do trabalho é importante para os homens e mulheres, mas o papel de ser avô/avó preenche igualmente a vida das mulheres e homens mais velhos. Portanto, ainda que os pais e avós não estejam próximos aos filhos/netos, outros familiares próximos ou voluntários podem exercer uma função importante nesses relacionamentos e trocas interpessoais.

A autoridade do velho nem sempre seja tolerada pelos mais jovens, que por vezes percebem a gerontocracia como fundamentada num poder abusivo, num saber ultrapassado e numa incompetência do presente ${ }^{17}$. Ainda assim, e principalmente porque há diferenças individuais, o convívio intergeracional é um dos mais valiosos instrumentos para a quebra de preconceitos, para a passagem de conhecimentos, ajuda mútua, solidariedade e amizade. Esta interação, quando prazerosa, pode favorecer o retardo da dependência, sobretudo física, e consequentemente, traduzir em uma economia de recursos, que são normalmente deslocados para o tratamento de idosos. Como apontado por França \& Soares ${ }^{7}$ os programas e as pesquisas intergeracionais possibilitam o resgate $d a$ autoestima, a atualização frente aos padrões, normas morais e sociais, a reciclagem frente aos novos conhecimentos e a continuidade das pessoas mais velhas como seres participativos $d a$ sociedade.

Numa perspectiva além da tomada de consciência do dever, a formação de valores éticos e morais depende de uma motivação interna para a ação. Trata-se dos sentimentos mais elevados que visam a uma vida boa e uma hierarquia de valores que se conservam. Tognetta $\&$ Vinha ${ }^{18}$ afirmam que, na filosofia clássica, por muito tempo a moral foi compreendida enquanto um conjunto de normas a serem seguidas e o bem e o mal, pensados como normas que vêm de fora, da religião, por exemplo. Nesse mesmo artigo, porém, citam Shaftesbury dizendo que, ao contrário, "é como a afeição natural, que amamos o bem ou queremos a moral, pois temos certas inclinações para amar” (p. 16). 
Para La Taille ${ }^{19}$ o tema virtude soa como um clássico da moralidade e do civismo, e alguns sinais parecem mostrar que o tema das virtudes talvez esteja renascendo: justiça, gratidão, fidelidade, generosidade e tolerância (virtudes morais); honra, coragem, polidez, prudência e humildade (virtudes de caráter). De que modo esses valores eram desenvolvidos em épocas anteriores?

O trabalho voluntário, por sua vez, é uma das formas de exercitar a moral e a cidadania, favorecendo as relações intergeracionais, unindo crianças, professores e idosos da comunidade; trabalhadores jovens e mais velhos e os aposentados, através das empresas, em função de uma proposta de ajuda mútua. França ${ }^{20}$ ressalta que o voluntariado é um exercício de cidadania, canal eficaz para a intergeracionalidade e disseminação de um senso de propósito para o bem-estar do próximo e do coletivo.

Alguns idosos podem ter disponibilidade para colaborar na educação não-formal de crianças/ jovens, bem como as crianças podem apoiar idosos dependentes. Os idosos podem ser atualizados, assistidos e apoiados pelos jovens, através de trocas intergeracionais que independem de laços familiares. Os jovens podem ser tutores de pessoas mais velhas em cursos que requeiram tecnologia, conhecimentos recém-adquiridos nas universidades ou mesmo que digam respeito a algo que já faz parte do dia a dia como a inserção digital. Há, portanto, uma gama enorme de alternativas de programas intergeracionais a serem desenvolvidos que propiciem a troca de conhecimentos, afetividade, o resgate de valores e de memória, a quebra de preconceitos e o estímulo a atitudes solidárias e cidadãs.

Quanto à formação das atitudes cidadãs, é importante lembrar que o "ser cidadão" é muitas vezes confundido pelo direito de votar. Entretanto, o ato de votar não garante nenhuma cidadania, se não vier acompanhado de determinadas condições de nível econômico, político, social e cultural, como apontado por Covre $^{21}$. Ser cidadão "significa ter direitos e deveres, ser súdito e ser soberano” (p. 9). Tal situação está descrita na Carta de Direitos da Organização das Nações Unidas (ONU) de 1948, que tem suas primeiras matrizes marcantes nas cartas de Direito dos Estados Unidos (1776) e da Revolução Francesa (1798) ${ }^{21}$.

A proposta de cidadania da Carta de Diretos da ONU é a de que todos os homens são iguais perante a lei, sem discriminação de raça, credo ou cor, cabendo a todos o domínio sobre seu corpo e sua vida, o acesso a um salário condizente para promover a própria vida, o direito à educação, à saúde, à habitação e ao lazer. E ainda, como apontado por Covre ${ }^{21}$ : é direito de todos poderem expressar-se livremente, militarem em partidos políticos e sindicatos, fomentarem movimentos sociais, lutarem por seus valores. Enfim, o direito de ter uma vida digna.

Recente pesquisa visando a verificar como os jovens compreendem o civismo e a cidadania, realizada em João Pessoa, Paraíba, por Moreira, Rique, Pontes e Rodrigues ${ }^{22}$, aponta que, de maneira geral, mesmo quando as definições de civismo e cidadania demonstrem conhecimento, as justificativas que visam a relacionar cidadania como comportamento cívico são precárias em elaboração. Interpretou-se essa falta de clareza na capacidade de relacionar civismo com a cidadania, como sendo uma expressão da transição na qual se encontram os valores de civismo. Os jovens ainda não assimilaram adequadamente como os valores ć́vicos se acomodam dentro de um conceito mais amplo, como é o de cidadania.

A Constituição* é uma arma na mão de todos os cidadãos, que devem saber usá-la para encaminhar e conquistar propostas mais igualitárias. Os direitos e deveres como conteúdo do exercício de cidadania são algo possível, mas depende do enfrentamento político adotado por quem tem pouco poder. Portanto, só existe

Constituição da República Federativa do Brasil de 1988. Disponível em URL: http://www.planalto.gov.br/ccivil_03/constituicao/ constitui\%C3\%A7ao.htm 
cidadania se houver a prática da reivindicação, da apropriação de espaços e fazer valer os direitos do cidadão.

A prática da cidadania deve ser a estratégia utilizada nas oportunidades a serem desencadeadas pelas atividades intergeracionais no Brasil, tendo em vista a construção de uma sociedade mais justa. $\mathrm{O}$ direito de reivindicar deve ser o primeiro pressuposto dessa prática. Este pressuposto deve ser ampliado a toda a população, podendo ser alcançado por meio da discussão dos direitos e dos deveres das diferentes gerações, tendo em vista as atitudes solidárias e cidadãs na comunidade.

Uma das maneiras que podem aproximar gerações é o desenvolvimento de atividades lúdicas e de caráter social, que possam ecoar dentre os interesses e realidade dos participantes. Assim, tais atividades devem ser complementadas por discussão e a troca de vivências e percepções dos idosos e crianças, facilitadas pelos professores das escolas. O relacionamento advindo das atividades, reflexões e discussões oferecerão oportunidades para o reforço à solidariedade intergeracional e às atitudes cidadãs.

Esta visão corrobora o que Freire ${ }^{23}$ reforçou diante da importância do contexto relacional na discussão da cidadania, argumentando que esta questão não se resume apenas ao fato de o cidadão votar, mas na necessidade de olhar a história, a partir de uma construção social e não individual. A cidadania, na perspectiva freiriana, corresponde ao "máximo de uma presença crítica no mundo da história por ela narrada." (p. 129). Deste modo, o conceito de cidadania se encontra "casado com o conceito de participação, de ingerência nos destinos históricos e sociais do contexto onde a gente está.” (p. 129).

Associado ao pensamento de Freire ${ }^{23}$ está a argumentação de Valente ${ }^{24}$, que segue no propósito de entender a cidadania moderna constituída junto com a ciência, a partir de uma análise que considere o "modo como articulamos esta forma especial do pensamento humano com as nossas dúvidas, os nossos receios, as nossas convicções ou as nossas crenças" sendo determinante "para a nossa intervenção como cidadãos” (p. 7).

No caso da relação professor-aluno, o caráter lúdico das atividades intergeracionais educacionais será uma fonte potencial de mediação de valores e construção da cidadania, em que ambas as partes aprendam com a troca de vivências e na interlocução de saberes. Em geral, o ambiente sociomoral das escolas requer que os alunos sejam "bem comportados". Esse tipo de educação, submisso e acrítico às regras, dificilmente contribui para situar valores. A aprendizagem e o contexto social, as vivências e as necessidades sentidas pelos participantes deverão estar presentes nas discussões. Portanto, as atividades alternativas que permeiem o lúdico e pedagógico devem ser o ponto de partida das sessões intergeracionais e parte ativa do processo de construção de novos conhecimentos e ainda de construção de uma sociedade melhor.

A interação obtida entre as atividades lúdicas e informativas e o processo dialético deverá ser permeada pelo estímulo constante à solidariedade e à cidadania. Quem educa tem a tarefa de formar para a autonomia, desenvolver a consciência, promover sensibilidade. A presença dos afetos é evidente para a constituição de um julgamento moral.

Apesar das dificuldades que a escola enfrenta para contribuir com a formação de personalidades éticas, hoje, mais do que em qualquer outra época, ela é o espaço por excelência das relações. Para cada atividade proposta, deverá sempre ser questionado até que ponto e de que forma ela irá contribuir para esta interação. Não devem ser impostas rotinas preestabelecidas, ou mesmo propor atividades que não possam contribuir para a quebra de preconceitos frente ao envelhecimento e o estímulo à solidariedade e à cidadania.

Braz da Silva et al..$^{25}$ analisaram as situações de ensino-aprendizagem, vivenciadas na escola, que, como instituição representativa do sistema educacional, se insere no contexto mais amplo da sociedade, sob a perspectiva de que a educação escolar possa "criar um espaço para que o sujeito se expresse e se diferencie por meio de uma 
dialética que o ligue às situações socialmente elaboradas" (p. 454).

A utilização das estratégias didáticas em uma perspectiva lúdica, como parte integrante do processo de ensino-aprendizagem, é fundamental. Tais estratégias nos permitem realizar um diagnóstico minucioso de todo o processo, facilitando a identificação dos pontos de entrave e das necessidades de superação. Isto é devido, em parte, ao caráter motivador e dialógico dessas estratégias, elementos que estabelecem situações de interação entre os participantes. Nesse sentido, muito mais que um momento fragmentado do processo educativo, elas estarão orientando o próprio processo de ensino-aprendizagem. Deste modo, possibilitará, não só a aferição dos resultados alcançados, mas, sobretudo, a seleção de novas prioridades, tendo em vista a diversificação dos cenários sócio-culturais nos quais a escola está inserida.

Ao se falar em aprendizagem, é necessário esclarecer que esta não ocorre apenas nos espaços formais, ou na comunidade onde residem os idosos e os participantes de outras gerações, mas também, e com muita abrangência atualmente, nos espaços ditos informais, como os museus e os centros de ciência, os planetários, os ambientes interativos didáticos, que envolvem teatros e jogos colaborativos, como o RPGs (rolling play games). A articulação de ações educativas entre espaços formais e não-formais tem potencial de promover uma interação social capaz não só alcançar melhores condições de ensino e aprendizagem, mas desenvolver atitudes de solidariedade e cidadania ${ }^{26}$.

O foco fundamental do trabalho intergeracional deve ser o processo educativo centrado na melhoria da comunidade, e dos que dela participam, por meio de uma troca de informações, percepções e conhecimentos, nas situações práticas, de forma criativa e de maneira a se obter as bases para as ultrapassagens conceituais relevantes. De nada adianta desenvolver em sala de aula um formalismo, seja matemático ou lógico, de um determinado problema, se este não se constitui enquanto problema para os participantes da comunidade.
É necessário que se sintam seduzidos para que encontrem significação a partir das atividades desenvolvidas.

A conceituação de Luckesi (Ramos, 2000)27, projeta o lúdico um contexto maior. É necessário entender o lúdico como um "fazer humano mais amplo" (p. 52), que para o autor não se relaciona apenas à presença de brincadeiras ou jogos, mas envolve uma atitude do sujeito na ação, em que pese o envolvimento genuíno do sujeito com a atividade. O caráter motivador, por exemplo, tem em vista despertar o interesse dos idosos e das crianças ou adolescentes, implica envolvê-los em algo que tenha significado para si e para a comunidade onde residem. É necessário que se sintam seduzidos pelo que lhes é apresentado, produzido no envolvimento com o mundo, na interação com o outro, no compartilhamento de experiências e saberes.

\section{Práticas intergeracionais que podem ser} replicadas

O novo perfil demográfico e as demandas crescentes, tanto para os idosos quanto para as crianças, apontam para o avanço de providências e estratégias nas áreas da saúde, educação e de desenvolvimento social. Quanto ao atendimento à população que envelhece, algumas ações sociais e educativas devem ser registradas. Dentre elas, destacam-se o Trabalho Social com Idosos no SESC, iniciado em na década de 70 , e que atende hoje a mais de 200 mil idosos em todo o país.

Em 1992, o SESC-Departamento Nacional implantou o projeto intergeracional Era uma vez... Atividades intergeracionais ${ }^{28}$. O projeto apresentou resultados positivos quanto ao entrosamento, solidariedade e afetividade entre as faixas etárias. A importância desse projeto foi reconhecida pela Organização das Nações Unidas $^{29}$, e ainda é desenvolvido nos centros de atividades do SESC em todo o Brasil, já tendo atendido a mais de dois mil participantes. $\mathrm{O}$ projeto tem por objetivo o estímulo à comunicação intergeracional, pelo intercâmbio de vivências e experiências entre ambas as gerações. 
Os grupos são formados por crianças e idosos, que se encontram sistematicamente em reuniões semanais sistemáticas. Nesses grupos são realizadas atividades pedagógicas, culturais e de lazer, permitindo a crianças e idosos reconhecerem-se enquanto indivíduos, independentemente das diferenças etárias existentes entre eles.

Inspiradas em dois projetos intergeracionais realizados pelo sistema SESC, duas dissertações de mestrado foram desenvolvidas. A monografia de Carvalho $^{30}$ utilizou o projeto do Departamento Nacional "Era uma vez... Atividades intergeracionais", e a outra, com os participantes do Programa "Gerações" do Sesc-Campinas ${ }^{31}$. Os resultados de Lima apontam a "geratividade" como a maior forma de cooperação que uma geração pode dar às outras, e que os programas intergeracionais são incentivadores da participação efetiva dos grupos etários na comunidade e no mundo, respeitando-se e reconhecendo as diferenças e semelhanças como parte da diversidade, enfraquecendo as discriminações. Já Carvalho confirmou que o instrumento da literatura infantil é providencial no desencadeamento dos diálogos e transmissão de saberes entre as gerações

A Universidade é um ambiente propício para se aproximar as gerações. Isto vem sendo notado a partir de 1990, quando foram criadas as universidades para a terceira idade ${ }^{20}$, que se espalharam por todo o Brasil e têm feito diferença no atendimento de idosos da comunidade, seja no âmbito ambulatorial, na oferta de atividades socioculturais, na realização de pesquisas, ou nos cursos de especialização e pós-graduação em Gerontologia. Os idosos tanto podem estar participando de cursos específicos para eles, quanto cursando graduação ou pós-graduação, misturando-se com jovens universitários. Podem também simplesmente buscarsua atualização, uma nova habilidade ou um conhecimento a ser aplicado num novo tipo de trabalho, ou mesmo na vida pessoal. Nas universidades, os programas intergeracionais podem ser desenvolvidos através das atividades de extensão e pesquisa, que ao mesmo tempo facilitem a aproximação das faixas etárias e possam avançar as pesquisas sobre relacionamento e os preconceitos sociais.
Dentre as medidas governamentais que merecem destaque na área do envelhecimento, estão a criação de delegacias especiais para os idosos; a melhoria e expansão dos serviços e dos programas de saúde do idoso; a gratuidade nos transporte e a redução de preços em atividades de lazer e cultura para os mais velhos, promovidas pelo governo federal, e pelas secretarias de estado e prefeituras. Complementando essas iniciativas, em outubro de 2003, foi promulgada a Lei $\mathrm{n}^{\circ} 10.741$, que estabelece o Estatuto do Idoso ${ }^{32}$ de vital importância para a proteção dos direitos dos idosos.

No que toca especificamente à intergeracionalidade, o Estatuto do Idoso ${ }^{32}$ reforça os seguintes aspectos:

Título I, Disposições preliminares, artigo $3^{\circ}$, parágrafo único, item IV, que dispõe sobre a prioridade na "viabilização de formas alternativas de participação, ocupação e convívio do idoso com as demais gerações";

Título II, Dos direitos fundamentais, Capítulo V, da Educação, Cultura e Lazer. No artigo 21, $\mathbb{S}$ $2^{\circ}$ : “Os idosos participarão das comemorações de caráter cívico ou cultural, para transmissão de conhecimentos e vivências às demais gerações, no sentido da preservação da memória e da identidade culturais." No artigo 22: "Nos currículos mínimos dos diversos níveis de ensino formal serão inseridos conteúdos voltados ao processo de envelhecimento, ao respeito e à valorização do idoso, de forma a eliminar o preconceito e a produzir conhecimentos sobre a matéria."

Essas medidas foram muito importantes para a qualidade de vida dos idosos, mas é preciso ir além e promover uma ação de inclusão mais efetiva, para evitar processos segregatórios, combater os preconceitos aos mais velhos. Para tal, é necessário que as gerações se aproximem, independentemente das relações familiares, e possam experienciar os benefícios desses contatos. Quando reforçados pela mídia, colaboram no processo de respeito e inclusão dos idosos.

Nos Estados Unidos e em outros países como França, Japão, Nova Zelândia e Austrália, os 
programas intergeracionais são mais frequentes e organizados tanto com a participação do governo, quanto pelas instituições sem fins lucrativos. Nos Estados Unidos, muitos estados promovem programas intergeracionais, como por exemplo o Departamento de Envelhecimento de Illinois, ${ }^{\mathrm{I}}$ que desenvolve um número considerável de programas intergeracionais. Uma instituição em Denver, a Rainbow Bridge ${ }^{\mathrm{II}}$ promove o relacionamento de idosos que estão nas instituições de longa permanência junto aos jovens, famílias e organizações da comunidade. Em Madison, existe o Wisconsin Intergenerational Network (WIN) ${ }^{\mathrm{II}}$, que promove o entendimento intergeracional através de programas de educação A AARP (Organização Americana de Aposentados) desenvolve o Grandparent Information Center ${ }^{\mathrm{IV}}$, fornecendo informações para os avós que estão educando seus netos e querem exercer seu papel positivamente

Há também organismos de âmbito internacional, tais como a Generations United ${ }^{\mathrm{V}}$ que oferecem uma relação de sites que disponibilizam programas intergeracionais bem planejados em diversos países, e apresentam inúmeros benefícios tanto para os jovens quanto para os mais velhos. Alguns programas empregam trabalhadores mais velhos por meio expediente, outros treinam voluntários mais velhos para atuarem em creches públicas ou privadas.

Outra modalidade de programa intergeracional que explora aventuras em torno da aprendizagem ao longo da vida é o Exploritas Intergenerational Programs ${ }^{\text {VI }}$, uma instituição internacional sem fins lucrativos de educação e turismo, criada para os adultos (avós, pais, tias, tios ou amigos da família) participarem de uma aventura de aprendizagem com seus parentes jovens ou amigos. Esses programas oferecem oportunidades para os avós conhecerem melhor seus netos, e para os tios e as tias e outros participantes que queiram dividir novas ideias, desafios e experiências importantes em cada fase que tiveram na vida. São oferecidos programas de aventura, turismo e lazer, voltados para a integração de faixas etárias diferentes, em prol de um mesmo interesse/ atividade.

Em 1999, foi criado a International Consortium for Intergenerational Programs (ICIP) ${ }^{\text {VII }}$, um consórcio internacional com a finalidade de promover programas intergeracionais através de uma abordagem sistemática de práticas, pesquisas e políticas públicas dentro de uma perspectiva global que promove uma série de eventos internacionais nesta área. $\mathrm{O}$ consórcio coaduna com a ideia de que os programas intergeracionais estimulam a formação de atitudes positivas sobre as pessoas mais velhas, o fortalecimento de relacionamentos através do ciclo da vida e a inclusão social de todas as gerações.

Em termos metodológicos, os programas intergeracionais podem ser realizados sistemática ou assistematicamente, mantidos sob a forma de parcerias, com a participação de organizações governamentais e não-governamentais. Qualquer que seja o tipo do programa e sua extensão, para ser bem-sucedido é preciso haver uma forte liderança entre as instituições que irão participar, comprometida com o resultado do trabalho. Como apontado por França ${ }^{28}$ o coordenador tem o papel fundamental de planejar e organizar as atividades intergeracionais, que podem ser lúdicas, pedagógicas, cidadãs, recreativas ou assistenciais. É dele também a responsabilidade pela escolha do local para sediar o programa, o mobiliário e estrutura apropriados, contando com recursos obtidos em parceria.

\footnotetext{
Disponível em URL: http://www.state.il.us/aging

Disponível em URL: http://www.rainbowb.org

II Disponível em URL: http://www.win.org/resources.htm

v Disponível em URL: http://www.aarp.org/grandparents

Disponível em URL: http://www.gu.org

Disponível em URL: http://www.exploritas.org/programs/intergenerational_default.asp

III Disponível em URL: http://www.icip.info/
} 
Os conteúdos de um programa intergeracional podem variar desde a visita sistemática de jovens a um hospital infantil ou de idosos, trabalho voluntário em uma creche comunitária, um sistema de transporte solidário, centros de recreação e escolas da comunidade, onde os mais velhos possam ser tutores de jovens, ou vice-versa. Cada pessoa tem uma ou mais habilidades, conhecimentos, aptidões, ou sabe desenvolver uma atividade, que pode ser multiplicada e dividida por outros que não são ou não foram tão afortunados. Um programa intergeracional, para ser bem-sucedido, precisa envolver um diagnóstico inicial sobre os interesses $\mathrm{da}$ comunidade, a ponderação entre os recursos disponíveis e os objetivos e metas a serem cumpridos. É preciso um treinamento básico para os participantes voluntários e equipe responsável pelo desenvolvimento das atividades do programa. Não menos importante é um sistema de avaliação permanente, que ofereça condições de sustentabilidade e de multiplicação das propostas. Um programa pode iniciar suas atividades com um grupo pequeno e ir se expandindo tanto no mesmo local quanto em outras comunidades.

As práticas intergeracionais vêm demonstrando que é possível efetuar uma mudança na mentalidade da comunidade em relação à imagem do idoso e o resgate da memória de um povo através de seu patrimônio vivo. Esses resultados podem e devem ser multiplicados por outras organizações públicas e privadas. Não menos importante está a intensificação das pesquisas acadêmicas para comprovar os benefícios intergeracionais destes programas.

\section{CONSIDERAÇÕES FINAIS}

Uma das conclusões da Assembleia Mundial de Madri foi o reconhecimento da importância decisiva dos programas intergeracionais para $o$ desenvolvimento social a interdependência, a solidariedade e a reciprocidade entre as gerações ${ }^{4}$. Um dos grandes benefícios destes programas é a quebra de preconceitos entre as gerações, tanto no âmbito cognitivo quanto no social e afetivo, mas outros benefícios culturais, psicossociais e de solidariedade poderão ser alcançados ${ }^{7,33}$. Diante de tantos benefícios, é fundamental que estas práticas intergeracionais sejam divulgadas pela mídia e desenvolvidas com maior intensidade pelas diversas instituições da sociedade.

Os programas intergeracionais devem ser propostos em esquema de parceria, pelas universidades, governo, organizações ou outras instituições sociais. As escolas talvez representem o espaço mais adequado para sua realização. Contudo, as organizações de trabalho, através das ações dos órgãos de recursos humanos, poderão facilitar a redução do preconceito contra os trabalhadores idosos, fomentando projetos que aproximem as gerações. Os mais velhos podem participar dos projetos de treinamento de pessoal, descrevendo uma tarefa específica, um caso significativo para a empresa, ou mesmo participar do repasse de conhecimentos ou da memória organizacional. A função social da mídia é reforçar uma imagem mais positiva do envelhecimento, e cobrar da sociedade mais atenção para aqueles que precisam de mais cuidados.

As universidades, por meio dos seus centros ou institutos de envelhecimento/gerontologia, universidades abertas da terceira idade ou programas de pós-graduação e extensão, podem devolver à comunidade os resultados das pesquisas, propondo atividades de extensão que integrem pessoas de diversas gerações. Podem facilitar ainda o desenvolvimento das relações interpessoais e a solidariedade, independentemente do gênero, idade, nível econômico, ou raça. Esse vasto campo de possibilidades inclui a formação de mão de obra para lidar com o rápido processo de envelhecimento, como os cuidadores de idosos. A universidade, ao adotar um programa intergeracional, além de promover os inúmeros benefícios para a comunidade, poderá cumprir a função social da academia, possibilitando a captação de recursos e investimentos, e o aprofundamento de pesquisas futuras nesta área. 


\section{REFERENNCIAS}

1. Instituto Brasileiro de Geografia e Estatísticas IBGE. Síntese dos indicadores sociais, estudos e pesquisas. Rio de Janeiro, 2006.

2. Jornal da Globo. Insegurança e drogas são os maiores problemas da educação brasileira. Rede Globo de Televisão; 2009.

3. Goldani AM. Relações intergeracionais e reconstrução do estado de bem-estar. Por que se deve repensar essa relação para o Brasil In: Camarano AA (Org.). Os novos idosos brasileiros. Rio de Janeiro: IPEA, 2004. p. 211250.

4. Nações Unidas. Relatório da $2^{\mathrm{a}}$ Assembleia Mundial sobre o Envelhecimento, Madrid;2002.

5. Mercy E, Schuengel C, Schulze H. Intergenerational Solidarity. An attachment perspective. Journal of Aging Studies; 2007; 21: 175-186.

6. Antonucci T. Social relations: a examination of Social Networks, Social Support, and Sense of Control. Handbook of Psychology of Aging; New York: Academic Press; 2007; 427-453.

7. França L, Soares N. A importância das relações intergeracionais na quebra de preconceitos sobre a velhice. In: Veras RP (Ed.). Terceira Idade: desafios para o terceiro milênio. Rio de Janeiro, BR: Editora Relume Dumará/Unati/ UERJ, 1997; 143-169.

8. Seminerio FL. Conflitos existenciais na terceira idade. Arq. Bras. Psicol. Aplicada: 1991; 43: 1-2.

9. Organização Mundial de Saúde.

Envelhecimento ativo: uma política de saúde. Brasília: Organização Pan-Americana da Saúde, 2005.

10. Erikson EH. Childhood and society . New York: Norton; 1963.

11. Mcadams DP, St.Aubin E. (Eds.). Generativity and adult development: how and why we care for the next generation. Washington, D.C. APA Press; 1998.

12. Mcadams DP, St. Aubin E. A theory of generativity and its assessment through selfreport, behavioral acts, and narrative themes in autobiography. Journal of Personality and Social Psychology; 1992; 62: 1003-1015.

13. Magalhães MO, Gomes W. Personalidades vocacionais, generatividade e carreira na vida adulta. Rev. Bras de Orientaç. VocacionaL, 2005; 6(2): 71-79.
14. Coleman PG, Podolskij A. Identity Loss and Recovery in the Life Stories of Soviet World War II Veterans. The Gerontologist; 2007.47(1): 52-60.

15. Schwarz B, Trommsdorff G, Albert I, Mayer B. Adult parent-child relationships: relationship quality, support and reciprocity. Applied psychology: an international review 2005: 54(3): 396-417.

16. Reitzes DC, Mutran E. Grandparent identity, intergenerational identity, and well-being. The Journals of Gerontology: Social Sciences, 2004. 59B(4); 213-219.

17. Dumazedier J. Contribution des personnes âgées a l'elaboration d'une societé des temps libre. Gerontologie et Societé, 1990; 55: 220-231.

18. Tognetta LRP, Vinha TP. Valores em crise: o que nos causa indignação? In: La Taille Y, et al. Crise de Valores ou Valores em Crise? Artmed, Porto Alegre-RS, 2009. 15-45.

19. La Taille Y. As virtudes segundo os jovens.: In: La Taille Y, et al. Crise de Valores ou Valores, 46-69.

20. França L. O desafio da aposentadoria. Rio de Janeiro; Rocco, 2008.

21. Coofler MLM. O que é cidadania. São Paulo: Brasiliense (Coleção Primeiros Passos), 2001.

22. Neto JR. O civismo em discussão: juventude e contemporaneidade de valores. . In.: La Taille Y, et al. Crise de Valores ou Valores em Crise? Artmed, Porto Alegre-RS, 2009. 89-105.

23. Freire P. Pedagogia dos sonhos possíveis. São Paulo: Editora UNESP; 2001.

24. Valente MO. Ensino das ciências e cidadania. In: VIII Encontro de ensino das ciências, Portugal: Ponta Delgada, 2000, [Acesso em: 20/07/2010] Disponível em: URL: http://www.educ.fc.ul.pt.

25. Silva AB, Mettrau M, Baretp M. O lúdico no processo de ensino-aprendizagem das Ciências. Rev Bras Estud. Pedagógicos, 2007; 88(220):445-458.

26. Gouvêa G, Leal MC. Uma visão comparada do ensino de ciência, tecnologia e sociedade na escola e em um museu de Ciência. Ciência \& Educação, 2001; 7(1): 67-84.

27. Ramos RL. Por uma educação lúdica. In: Luckesi CC (Org.). Ensaios de Ludopedagogia, 1, Salvador: UFBA/FACED, 43-60.

28. França L. Programas Intergeracionais - Do conceito à Metodologia, Apresentação no XII Congresso Brasileiro de Geriatria e Gerontologia, Brasília powerpoint, 1999. 
29. Nações Unidas. Once upon a time intergenerational activities. Bulletin on Aging, 1, New York, 1995; 11

30. Carvalho C. O diálogo intergeracional entre idosos e crianças: projeto "Era uma vez... atividades intergeracionais. [Tese]. Pontifícia Universidade Católica, Serviço Social; 2007.

31. Lima C. Programas intergeracionais : um estudo sobre as atividades que aproximam as diversas gerações.[ Tese de Mestrado]. Universidade Estadual de Campinas. Departamento de Educação; 2007.
32. Ministério da Saúde. Estatuto do Idoso, Série E, Legislação de Saúde. 1a. edição, 2a. reimpressão, Brasília, 2003.

33. Kingson E, Hirshorn B, Harootyan LK. The common stake: the interdependence of generations : A policy framework for an aging society. Washington, D.C.: The Gerontological Society of America. Reprinted in H.R. Moody (1994), Aging: Concepts and controversies Thousand Oaks, California, Pine Forge Press, (1987). 
